\title{
Antibiotics and antivirals do not modify experimentally-induced Creutzfeldt-Jakob disease in mice
}

\author{
J U N T A T E IS H I \\ From the Department of Neuropathology, Neurological Institute, Faculty of Medicine, \\ Kyushu University, Fukuoka, Japan
}

SUMMARY Thiamphenicol, rifampicin, amantadine, cytosine arabinoside and isoprinosine were administered to mice which were inoculated with brain tissue containing Creutzfeldt-Jakob disease (CJD). All the mice developed disease within 3 to 6 months after inoculation. As there was no significant shift in incubation periods among animal groups of each drug administration and non-administration, these compounds had no effect in controlling experimental CJD.

Creutzfeldt-Jakob disease (CJD) is a human disease in a group of "unconventional virus" infections of the CNS that includes kuru in New Guinea, scrapie in sheep and transmissible mink encephalopathy. CJD has been transmitted to chimpanzees and other primates, ${ }^{1}$ and recently to small rodents. ${ }^{2-4}$ Direct transmission from patients to mice and rats, and successive propagations were carried out for the first time in our laboratory. ${ }^{4}$ Using this experimental animal system, we studied the modifying effects of antibiotics and antiviral compounds including amantadine which was reported to have therapeutic effect on CJD patients. $^{56}$ Other antivirals, including rifampicin, cytosine arabinoside (Ara-C) and isoprinosine (Inosiplex, Viruxan) were also studied. Thiamphenicol was chosen as an example of a broadspectrum antibiotic.

\section{Methods}

Thirty $\mathrm{mg}$ per $\mathrm{kg}$ of Ara-C was injected intraperitoneally three times weekly, while other compounds were dissoved in drinking water and given ad libitum until the onset of the illness. Daily doses of thiamphenicol, rifampicin and amantadine were approx.

Address for reprint requests: Dr J Tateishi, Department of Neuropathology, Neurological Institute, Faculty of Medicine, Kyushu University, Fukuoka 812, Japan.

Accepted 16 June 1981
100,90 and $160 \mathrm{mg}$ per $\mathrm{kg}$, respectively. Three doses of isoprinosine were shown in the table. Two days after administration of the compounds, white (CF 1, DDD) and black (C57BL) mice were injected intracerebrally $0.01 \mathrm{ml}$ of $10^{-1}$ dilutions in saline of brain homogenates from affected mice. Mouse passage CJD agents were procured from two patients KF and BY whose clinicopathological details were reported elsewhere. ${ }^{7}$ Control mice were inoculated with the same homogenates as the test group, though not given the compounds. The experiments were performed on two occasions and after the onset of clinical symptoms, all animals were killed for pathological verification of the diagnosis.

Table Treatments and incubation periods (days: $M \pm S D$ )

\begin{tabular}{|c|c|c|c|c|}
\hline $\begin{array}{l}\text { A } \\
\text { Treatment }\end{array}$ & \multicolumn{2}{|c|}{$\begin{array}{l}C F 1 \\
\text { mouse } / K F^{*}\end{array}$} & $\begin{array}{l}\text { C57BL } \\
\text { mouse/KF }\end{array}$ & $\begin{array}{l}\text { C57BL } \\
\text { mouse/BY }\end{array}$ \\
\hline $\begin{array}{l}\text { Brain emulsion } \\
\text { +Thiamphenicol } \\
\text { +Rifampicin } \\
\text { +Amantadine } \\
\text { +Ara-C }\end{array}$ & $\begin{array}{l}124.7 \pm 8 . \\
137.0 \pm 12 \\
122.4 \pm 1 . \\
128.0 \pm 9 . \\
121.8 \pm 7 .\end{array}$ & $\begin{array}{l}(9: \\
1(6) \\
(6) \\
(4) \\
(6)\end{array}$ & $\begin{array}{l}166.4 \pm 3.3(5) \\
160.8 \pm 10.4(5) \\
166.4 \pm 3.3(5) \\
166.4 \pm 3.3(5) \\
164.6 \pm 3.8(5)\end{array}$ & $\begin{array}{l}143.5 \pm 2.2(4) \\
145.8 \pm 2.3(5) \\
148.2 \pm 3.9(5) \\
145.8 \pm 4.3(5) \\
143.8 \pm 2.7(5)\end{array}$ \\
\hline $\begin{array}{l}B \\
\text { Treatment }\end{array}$ & \multicolumn{3}{|c|}{$\begin{array}{l}\text { CF } 1 \\
\text { mouse/BY }\end{array}$} & $\begin{array}{l}\text { CF I } \\
\text { mouse/KF }\end{array}$ \\
\hline $\begin{array}{l}\text { Brain emulsion } \\
\text { + Isoprinosine } 100 \\
\text { +Isoprinosine } 300 \\
\text { + Isoprinosine } 600\end{array}$ & $\begin{array}{l}\mathrm{hg} / \mathrm{kg} / \text { day } \\
\mathrm{ig} / \mathrm{kg} / \text { day } \\
\mathrm{ig} / \mathrm{kg} / \text { day }\end{array}$ & \multicolumn{2}{|c|}{$\begin{array}{l}124.0 \pm 10.4(5) \\
123.8 \pm 9.0(5) \\
126.0 \pm 11.4(5)\end{array}$} & $\begin{array}{l}104.2 \pm 14.8(5) \\
113.4 \pm 15.6(5) \\
115.4 \pm 11.3(5)\end{array}$ \\
\hline
\end{tabular}

*Inoculated animal/CJD patient

( ) Number of animals 


\section{Results}

All the animals developed the disease after the incubation periods shown in the table. None of the compounds produced a statistically significant shift in the incubation periods. A distinct sign in the diseased mice was plasticity of the body and tail, as noted previously. ${ }^{4}$ Spongiform change and proliferation of astrocytes were common pathological findings, though the distribution of the lesion in mice depended upon which of the two CJD agents had been inoculated. There was no distinct difference between clinicopathological features of control and test groups.

\section{Discussion}

Unconventional properties of the mouse passage CJD agents had been inoculated. ${ }^{7}$ There was no previously and the infectivity titre $\left(\mathrm{LD}_{50}\right)$ was between $10^{7}$ and $10^{8}$ per gram of mouse brain. ${ }^{8}$

Recently, amantadine has been administered to CJD patients and improvement or delayed worsening of clinical symptoms has been described. ${ }^{5}{ }^{6}$ In this experiment, however, no difference was found between test and control animals. As there was no major shift in the incubation period, the administered compounds had no effect in controlling experimental CJD. Hitherto, antiviral compounds have not been tested systematically in experimental CJD, due to limitations of susceptible an1mal species and long incubation periods. In our experiments, the disease was induced in the mice within 3-6 months after intracerebral inoculation, thus making it feasible to carry out further systemic studies of this morbid disease.

The author is grateful to Miss $\mathrm{K}$ Hatanaka, Miss $\mathrm{K}$ Beppu, and Miss A Ono for excellent technical and secretarial assistance. Isoprinosine used in this study was supplied by Mochida Pharmaceutical Co. The work was supported in part by a grant from the Welfare Ministry of Japan.

\section{References}

1 Gibbs CJ, JR, Gajdusek DC, Asher DM, et al. Creutzfeldt-Jakob disease (subacute spongiform encephalopathy): transmission to the chimpanzee. Science 1968; 161:388-9.

2 Manuelidis EE, Manuelidis L. Clinical and morphological aspects of transmissible CreutzfeldtJakob disease. In: Zimmerman HM, ed. Progress in Neuropathology, vol 4. New York: Raven Press 1979; 1-26.

3 Mathews WB, Tomlinson AH, Hughes JT. Transmission of Creutzfeldt-Jakob disease to guineapigs. Lancet 1979; 2:752.

4 Tateishi J, Sato Y, Koga M, Doi H, Ohta M. Experimental transmission of human subacute spongiform encephalopathy to small rodents. I. Clinical and histological observations. Acta Neuropathol (Berl) 1980; 51:127-34.

5 Sanders WL. Creutzfeldt-Jakob disease treated with amantadine. J Neurol Neurosurg Psychiatry 1979; 42:960-1.

6 Sanders WL, Dunn TL. Creutzfeldt-Jakob disease treated with amantadine. A report of two cases. J Neurol Neurosurg Psychiatry 1973; 36: $581-4$.

7 Tateishi J, Doi H, Sato Y, Suetsugu M, Ishii N, Kuroiwa Y. Experimental transmission of human spongiform encephalopathy to small rodents. III. Transmission from three additional patients and peculiar distribution of lesions in mice. Acta Neuropathol (Berl) 1981; 53:161-6.

8 Tateishi J, Koga M, Sato Y, Mori R. Properties of the transmissible agent derived from chronic spongiform encephalopathy. Ann Neurol 1980; 7:390-91. 
Atlas of the Human Brain Stem and Spinal Cord. By James D Fix and Carroll S Punte. (40 plates; $£ 12 \cdot 95$.) Distributed by MTP Press Ltd, Lancaster, 1981.

There have been several recent illustrated text books of human neuroanatomy and in reviewing this latest work on the anatomy of the brain stem and spinal cord one naturally makes comparisons with previous publications. One difficulty is to decide the readership for which this text is intended. It would be useful to a medical student, since the level of treatment of the subject is elementary, but one wonders why a student would buy an anatomical atlas on such a specialised area and if the price of $£ 12.95$ would not be too high.

The production is generally excellent with good reproduction of plates and a sensible lie-flat spiral binding in paperback. The pictures show the spinal cord in transverse sections stained for myelin at five levels. There is some technical error either in the staining or in the reproduction of plate 3 . A neuropathologist, neurosurgeon, neurologist or spinal therapist would require more segmental levels than those illustrated. The anatomist would be interested in additional Nissl stains to see more clearly the neuronal bodies making up the neuronal pools. The brain stem is shown in sections transverse to the neuraxis but in addition there are pictures of sections in the parasagittal, frontal and horizontal planes. These last mentioned pictures are particularly useful and show well the various neuronal structures in the brain stem and nearby parts of the brain and cerebellum. Again to see neuronal cell bodies in a cell stain such as Nissl would be helpful. The terminology is described as American vernacular but is a mixture of Latin and English and is unobjectionable, apart from the use of dorsal and ventral for posterior and anterior. The section on anatomical localisation and clinical presentation of the various spinal cord and brain stem syndromes is interesting but common to several rival publications. This part would be of great use to clinical medical students. The index is adequate for the type of book.

In summary, an elementary atlas, excellent in its way but expensive and specialised. Its greatest use would be as a manual for medical students to be given out in a practical class for a half day devoted to the anatomy of the spinal cord and brain stem.
Acta Neuropathological/Supplementum 7 Experimental and Clinical Neuropathology. Edited by $\mathbf{K}$ Jellinger, F Gullotta, M Mossakowski. (Pp 409; \$87.20.) Berlin: Springer-Verlag, 1981.

The Seventh Supplementum of Acta Neuropathologica contains the abstracts of the papers delivered at the First European Neuropathology Meeting held in Vienna in May, 1980. These short reports are grouped according to the subjects of neuro-oncology, infections and demyelinating diseases, metabolic disorders, peripheral nerve pathology and myopathology. Under the heading of experimental and clinical neuropathology, which has become the slightly overambitious title of the proceedings, are accommodated abstracts covering a wide field of topics. Some of the reports are new, others not so, and the overall standard varies greatly. The reproduction of the illustrations, particularly of the electron micrographs, are consistently of excellent standard. The variety of subjects makes the turning of the pages of this book rewarding, but the price to pay to satisfy cursory interest is prohibitive.

P LANTOS

Recent Advances in EEG and EMG Data Processing. Edited by Nariyoshi Yamaguchi and Kiyoshi Fujisawa. (Pp 408; US\$72.25, Dfl148.) Amsterdam: Elsevier/North Holland Biomedical Press, 1981.

This book includes 37 papers on methods of analysis of spontaneous EEG, evoked potentials and EMG given at the International Conference on EEG and EMG Data Processing held in Japan in September 1981.

The standard is somewhat uneven and the clinical yield appears to be rather small for the amount of work presented. However it is a useful and up to date guide to methodology for the specialist.

RG WILLISON

\section{Notices}

The International Conference of the Neurotraumatology Committee of the World Federation of Neurosurgical Societies, on Recent Advances in Neurotraumatology, will be held in the University of Edinburgh, Scotland, 20-22 September 1982. Organising Secretary (INCRAN), Department of Surgical Neurology, Western General Hospital, Edinburgh, Scotland.

The Fifth International Symposium on Brain Edema will be held in Groningen, Netherlands, 10th-12th June, 1982. Information may be obtained from the Symposium Secretariat, PO Box 252, 6710 BG EDE, The Netherlands.

\section{CORRECTION}

In the paper by Dr Tateishi, "Antibiotics and antivirals do not modify experimentally-induced Creutzfeldt-Jakob disease in mice" ( $J$ Neuro Neurosurg Psychiatry $1981 ; 44: 723-4)$, the first sentence under Discussion should read"Unconventional properties of the mouse passage CJD agent derived from patient KF were reported previously and the infectivity titre $\left(\mathrm{LD}_{50}\right)$ was between $10^{7}$ and $10^{8}$ per gram of mouse brain." 